\title{
The Electrical Resistivity and Acoustic Emission Response Law and Damage Evolution of Limestone in Brazilian Split Test
}

\author{
Xinji Xu, Bin Liu, Shucai Li, Jie Song, Ming Li, and Jie Mei \\ Geotechnical and Structural Engineering Research Center, Shandong University, Jinan, Shandong 250061, China \\ Correspondence should be addressed to Bin Liu; liubin0635@163.com
}

Received 13 June 2016; Revised 12 September 2016; Accepted 22 September 2016

Academic Editor: Antonio Riveiro

Copyright (C) 2016 Xinji Xu et al. This is an open access article distributed under the Creative Commons Attribution License, which permits unrestricted use, distribution, and reproduction in any medium, provided the original work is properly cited.

\begin{abstract}
The Brazilian split test was performed on two groups of limestone samples with loading directions vertical and parallel to the bedding plane, and the response laws of the electrical resistivity and acoustic emission (AE) in the two loading modes were obtained. The test results showed that the Brazilian split test with loading directions vertical and parallel to the bedding showed obviously different results and anisotropic characteristics. On the basis of the response laws of the electrical resistivity and $\mathrm{AE}$, the damage variables based on the electrical resistivity and AE properties were modified, and the evolution laws of the damage variables in the Brazilian split test with different loading directions were obtained. It was found that the damage evolution laws varied with the loading direction. Specifically, in the time-varying curve of the damage variable with the loading direction vertical to the bedding, the damage variable based on electrical resistivity properties showed an obvious damage weakening stage while that based on AE properties showed an abrupt increase under low load.
\end{abstract}

\section{Introduction}

Composed of various minerals, rock is a common engineering material with complex mechanical properties. Mainly controlled by tensile and compressive stress, the failure behaviors of rock under stress are highly complex. The tensile strength of rock (especially for coal) is far less than its compressive strength, and a lower tensile stress level can cause brittle fracture, which seriously threatens the safety and stability of the engineering structure. Therefore, studies on rock tensile failure are of great significance for underground engineering including tunnel, underground chamber, and coal mining [1].

In the loading process of rock, microcracks inside it constantly initiate, propagate, and even gradually interconnect to form macrocracks and cause macrofracture. So studies with only conventional mechanics methods are far from enough. In recent years, the electrical resistivity and $\mathrm{AE}$ methods are applied to studies on the failure process of rock $[2,3]$. The Brazilian split test is a standard method to determine the tensile strength of rock [4]. Studies on the response laws of the electrical resistivity and $\mathrm{AE}$ during the failure process are of great value, which help to understand the rock failure mechanism and to analyze the field real-time monitoring data of electrical resistivity and $\mathrm{AE}$.

Electrical resistivity is an important geophysical parameter of rock [5-8] and it changes as cracks develop in rock loading process. Since the 1960s $[9,10]$, scholars have studied the electrical resistivity response laws of rock in loading process. However, most of the studies were conducted on the electrical resistivity response laws of rock under pressure instead of tension, and related reports have not been seen.

Moreover, as rock split, the initiation and propagation of cracks would produce $\mathrm{AE}$, and $\mathrm{AE}$ signals carried much information about the failure [11-13]. Mlakar et al. 1993 [14] and Eberhardt et al. 1997 [15] studied AE properties and the relation between $\mathrm{AE}$ events and crack propagation during the failure process of rock and predicted the crack propagation laws according to their previous studies. Yu et al. 2007 [16] studied the differences of AE properties in the Brazilian split test, direct tensile test, and uniaxial compression test and compared the number of $\mathrm{AE}$ events in these three failure processes. Xie et al. 2010 [17] studied the impact of delaying cyclic loading and unloading time in the split test on rock Kaiser effect. Luo et al. 2010 [18] studied AE properties of different kinds of rock (three kinds of sandstone) and 
compared their tensile strength, cumulative AE count, and cumulative energy. Fu et al. 2011 [19] researched and found that AE accompanied the entire split process of the coal sample and showed different characteristics in different loading stages. Xie et al. 2011 [20] studied the spatial distribution characteristics of $\mathrm{AE}$ events in rock samples during the failure process and determined the relation between spatial distribution and stress as well as energy release. Wang et al. 2014 [21] established a mesolevel method to simulate AE in the Brazilian split test according to the moment tensor theory. The numerical calculation results agree well with the sample experimental results. As the main structural plane of rock, the bedding plane has a huge impact on the failure mechanism and mode of rock. However, most of the preceding studies concentrate on the AE response laws of rock in the Brazilian split test without considering the impact of the bedding direction on the laws.

Therefore, in this paper, limestone samples with obvious bedding were selected to study the response laws of the electrical resistivity and AE during the loading process in the Brazilian split test with loading directions vertical and parallel to the bedding. Moreover, the response laws in different loading directions were compared, and the impact of the loading direction on the Brazilian split test was analyzed. On that basis, the Brazilian split damage variables based on the electrical resistivity and AE properties were modified, and the failure laws of rock samples during the splitting process were further studied. This paper aimed to introduce some new ideas to experimental studies on the limestone in Brazilian split test by considering the electrical resistivity and $\mathrm{AE}$ response law and the damage evolution. We hope this paper can provide a reference for subsequent study on rock materials' properties and engineering practices.

\section{Test Scheme}

In the test described in this paper, limestone samples with a $50 \mathrm{~mm}$ diameter and height ranging from $50 \mathrm{~mm}$ to $60 \mathrm{~mm}$ were selected from a tunnel in Guangxi, China. The sample preparation precision meets related specifications.

Rock samples were divided into two groups with 20 in each group to perform the Brazilian split test. For one group, the loading direction is vertical to the bedding direction while for the other one, the loading direction is parallel to the bedding direction, as shown in Figure 1. The test equipment adopted the electrohydraulic servo rock rigid testing machine at a $200 \mathrm{~N} / \mathrm{s}$ loading speed. A typical stress-time curve in the test is shown in Figure 2. In the test, the electrical resistivity and AE signals of samples were simultaneously collected.

The electrical resistivity of rock samples was tested by using the device, as shown in Figure 3(a). In the horizontal direction of rock samples, $A$ and $B$ represent strip powering electrodes and $32 \mathrm{~V}$ constant voltage was applied between them. $\mathrm{M}$ and $\mathrm{N}$ are a pair of measuring electrodes to acquire the potential differences during the rock loading process. To reduce the contact resistance, clay was used as couplant between the electrodes and rock samples. The test device was wrapped with plastic film to prevent current passing through the test mould and press machine.

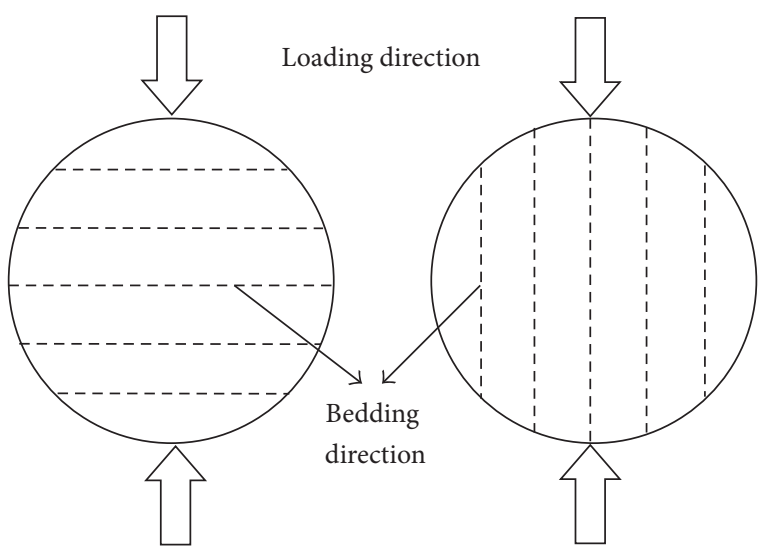

FIGURE 1: Diagram of loading directions.

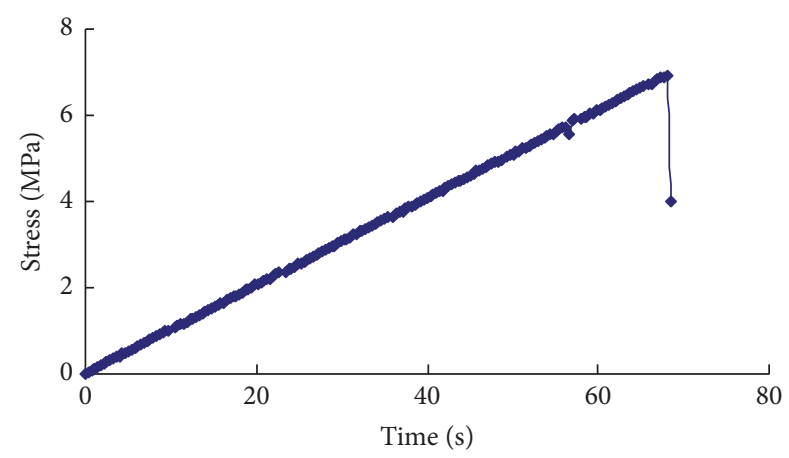

Figure 2: Stress-time curves.

The PCI- 8 AE system produced by American Physical Acoustics Corporation (PAC) was used to collect the AE signals in real time during the loading process. The AE sensor was pasted on one side of the rock sample with silica gel, as shown in Figure 3(b). Its center frequency is $60 \mathrm{KHz}$ and the frequency ranges from $35 \mathrm{KHz}$ to $100 \mathrm{KHz}$. The sampling frequency is set to $1 \mathrm{MHz}$ and preamplifier gain is $40 \mathrm{~dB}$. In addition, the environmental noise level should be calibrated before test to reduce its impact.

\section{Test Results and Analysis}

3.1. Test Results with the Loading Direction Vertical to the Bedding. Figure 4 shows the test results with the loading direction vertical to the bedding plane. Figures $4(\mathrm{a})-4(\mathrm{~d})$ show, respectively, the axial stress-strain curve and timevarying curves of the electrical resistivity, $\mathrm{AE}$ count rate, and cumulative AE count. According to these test results, the response laws of the electrical resistivity and $\mathrm{AE}$ in the Brazilian split test with the loading direction vertical to the sample bedding were obtained as follows:

(1) The entire loading process was divided into three stages: compaction, elastic deformation, and plastic deformation and failure.

(2) In the compaction stage, the electrical resistivity declined at a relatively slow rate; meanwhile, obvious $\mathrm{AE}$ activities appeared. 

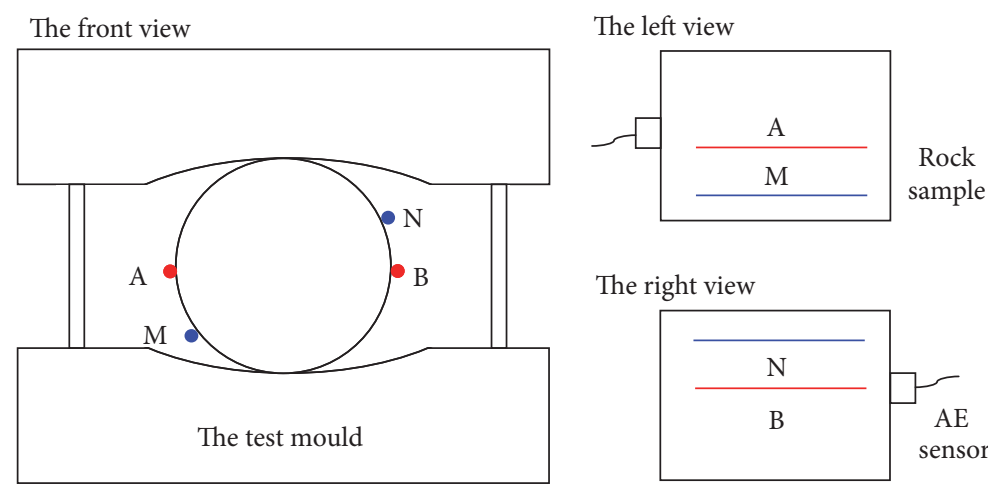

The right view

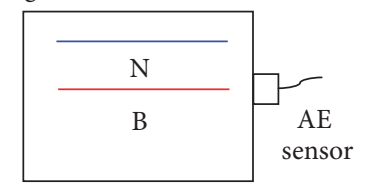

(a) Sketch map of experimental equipment
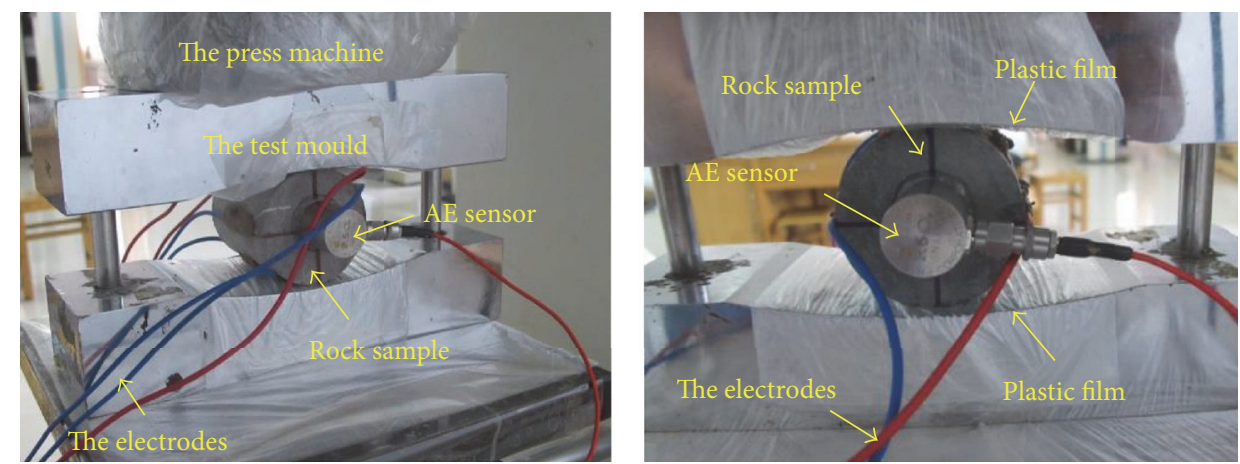

(b) Photo in the test

FIgURE 3: Experimental device.

This is because those microcracks inside rock samples were gradually compacted and closed under the load. As a result, the connectivity of the crack conductor in rock samples was improved; meanwhile, the contact between rock matrices (mineral particles) and between the matrices and pore water was increased, which improved the overall conductivity of rock samples and slowly brought down the electrical resistivity. Simultaneously, the compaction and closure of microcracks produced obvious AE activities.

(3) In the elastic deformation stage, the electrical resistivity basically remained unchanged or declined slightly; AE activities appeared at a lower level; the cumulative AE count increased slowly.

(4) In the plastic deformation and failure stage, the electrical resistivity increased at a relatively fast rate, and $\mathrm{AE}$ activities also increased gradually. This is because those microcracks inside rock samples further propagated and dilated as the load increased. As a result, the connectivity of the crack conductor was affected; the contact between rock matrices and between the matrices and pore water was decreased; the electrical resistivity of rock increased. Simultaneously, the propagation of cracks made AE activities gradually become active. As the load continued to increase, the microcracks inside rock samples continuously propagated. As a result, different cracks interconnected, forming a large crack. Rock would suddenly fail along with the large crack formed. Then, the electrical resistivity, together with the $\mathrm{AE}$ count rate and cumulative $\mathrm{AE}$ count, showed an abrupt increase. Prior to rock failure, the number of $\mathrm{AE}$ activities decreased, which is called "quiet period" in related literatures and is also an omen of rock failure.

3.2. Test Results with the Loading Direction Parallel to the Bedding. Figure 5 shows the test results with the loading direction parallel to the bedding plane. Figures 5(a)-5(d) show, respectively, the axial stress-strain curve and timevarying curves of the electrical resistivity, $\mathrm{AE}$ count rate, and cumulative AE count. According to these test results, the response laws of the electrical resistivity and $\mathrm{AE}$ in the Brazilian split test with the loading direction parallel to the sample bedding were obtained as follows:

(1) Significantly different from the Brazilian split test with the loading direction vertical to the bedding, the entire loading process consisted of the elastic deformation stage as well as plastic deformation and failure stage without an obvious compaction stage.

(2) The elastic deformation stage of rock samples lasted from initial loading until the occurrence of plastic deformation. In this stage, the electrical resistivity basically remained unchanged or declined slightly at the beginning of loading. In the early loading stage, AE activities barely appeared; as the load increased, a small number of AE activities began to appear but at a lower level. 


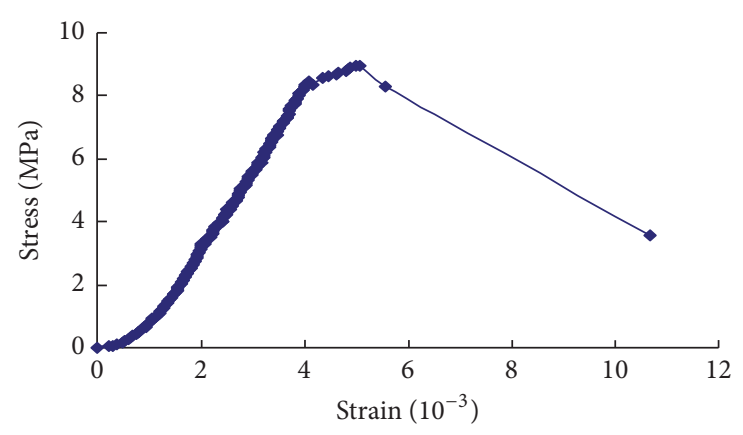

(a) Axial stress-strain curve

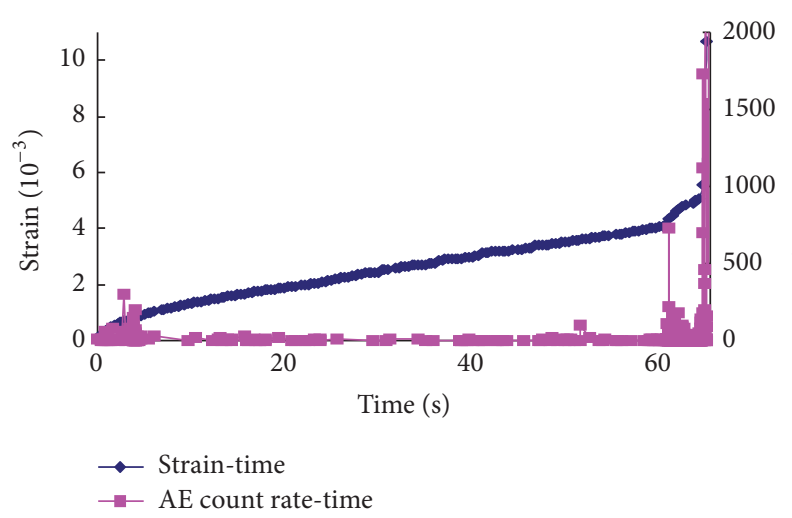

(c) Time-varying curve of the AE count rate

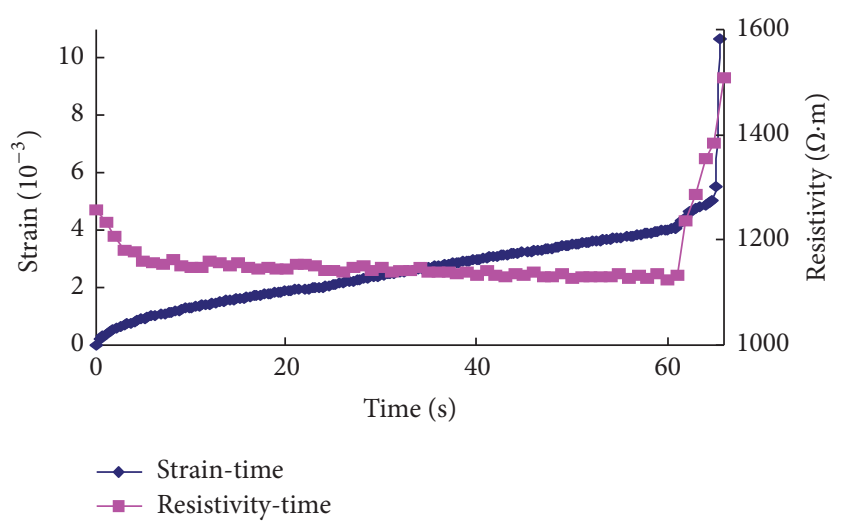

(b) Time-varying curve of the electrical resistivity

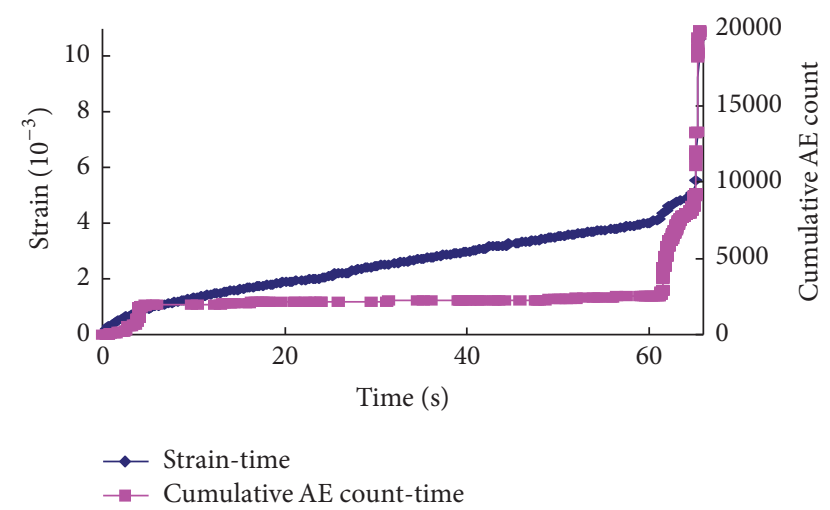

(d) Time-varying curve of the cumulative AE count

FIGURE 4: Test results of samples whose loading directions are vertical to the bedding plane.

(3) In the plastic deformation and failure stage, the response laws of the electrical resistivity and $\mathrm{AE}$ were basically consistent with those in the Brazilian split test with the loading direction vertical to the bedding. However, the AE count was notably greater and $\mathrm{AE}$ activities were more abrupt.

3.3. Comparative Analysis on Test Results with Loading Directions Vertical and Parallel to the Bedding. The Brazilian split test with loading directions vertical and parallel to the bedding shows obviously different results. Specifically, the stress-strain curve of the latter does not show the compaction stage, and the time-varying curve of the electrical resistivity of the latter does not show a slow decrease obviously in the early loading stage. Moreover, the time-varying curve of $\mathrm{AE}$ properties of the former indicates obvious $\mathrm{AE}$ activities while that of the latter indicates few ones. That is, the timevarying curve of the $\mathrm{AE}$ count rate of the former shows high counts (200-400) in the early loading stage while that of the latter shows low counts (0-10); the time-varying curve of the cumulative $\mathrm{AE}$ count of the former shows an abrupt increase in the early loading stage while that of the latter basically remains unchanged.

That is because the directional structural plane inside the stratified rock samples employed in this test has anisotropic failure and deformation mechanisms. When the loading direction is vertical to the bedding (i.e., the loading direction is the same as the normal direction of the structural plane), the cracks inside the structural plane of stratified rock samples are compacted and closed under the load, and there is an obvious compaction stage prior to the elastic deformation stage in the axial stress-strain curve. When the loading direction is parallel to the bedding (i.e., the loading direction is vertical to the normal direction of the structural plane), the force acting on the structural plane of stratified rock samples is parallel to the structural plane; therefore, the structural plane is barely compacted, and there is no obvious compaction stage in the axial stress-strain curve.

\section{Analysis on Damage Evolution}

On the basis of previous study results, the damage variables based on the electrical resistivity and AE properties were used to further study the failure laws of rock samples in the Brazilian split test according to damage mechanics in this paper.

4.1. Brazilian Split Damage Variables Based on the Electrical Resistivity and AE Properties. Li et al. 2014 [2] proposed the uniaxial compression damage model based on electrical resistivity properties. By reference of their thoughts, this 


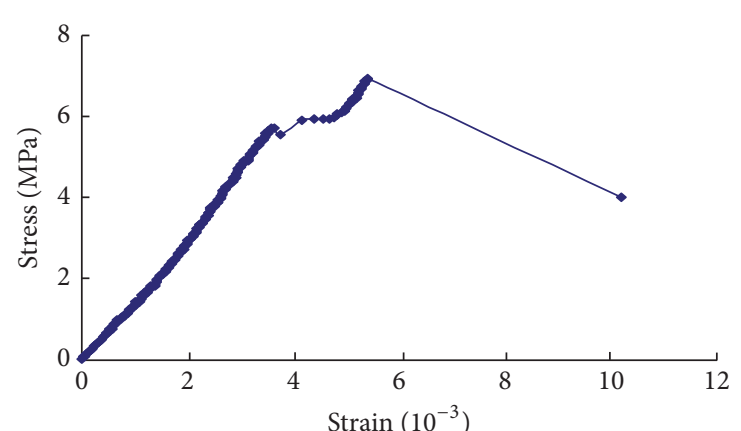

(a) Axial stress-strain curve

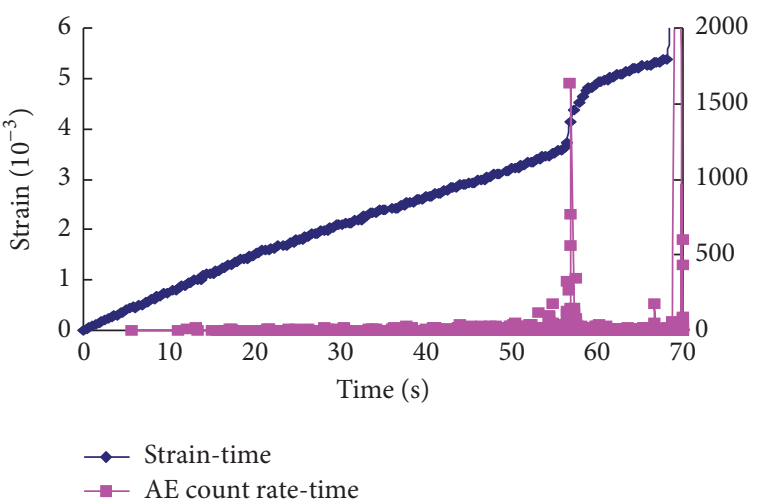

(c) Time-varying curve of the AE count rate

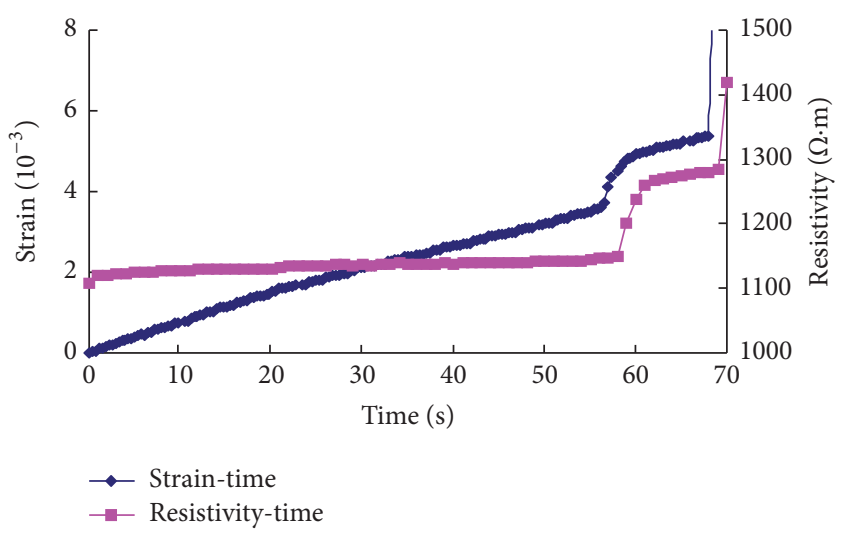

(b) Time-varying curve of the electrical resistivity

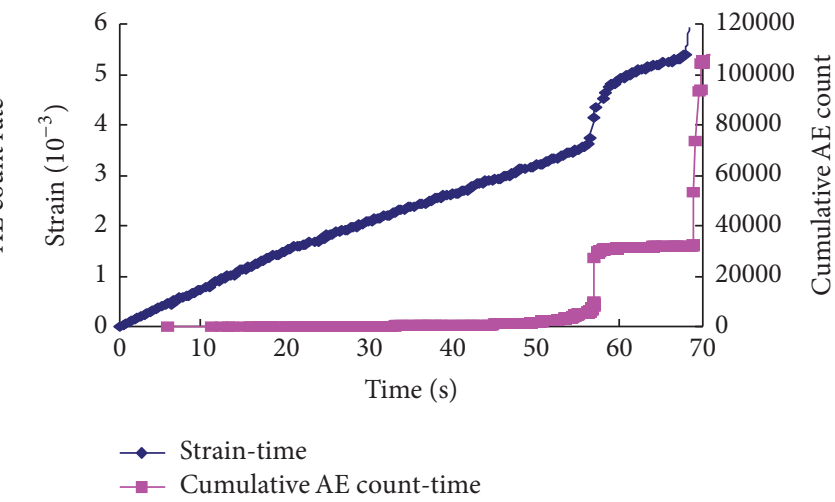

(d) Time-varying curve of the cumulative AE count

FIGURE 5: Test results of samples whose loading directions are parallel to the bedding plane.

paper established the damage variable $D_{\varphi}$ based on electrical resistivity properties:

$$
D_{\varphi}=\frac{\varphi_{0}-\varphi}{\varphi_{0}-\varphi_{s}}
$$

where $\varphi_{0}$ is the porosity of rock samples without load; $\varphi_{s}$ is the porosity of rock samples at failure; $\varphi$ is the porosity of rock samples at any time in the Brazilian split test. The electrical resistivity is expressed by the following equation:

$$
\varphi=\frac{3 \rho_{R}}{\rho_{A}+2 \rho_{R}},
$$

where $\rho_{A}$ is the electrical resistivity of air, and $\rho_{R}$ is the electrical resistivity of rock samples.

The damage variable based on electrical resistivity properties obtained by using (1) is a negative value in the compaction and elastic deformation stage. This is because rock samples without load are regarded as having no damage during formula deduction. Actually, rock samples without load have initial damage due to the existence of microcracks. Therefore, at the end of the elastic stage (i.e., the electrical resistivity is the lowest), rock samples are regarded as having no damage in this paper. In (1), $\varphi_{0}$ is modified to the porosity at the end of the elastic stage.

Liu et al. 2009 [22] proposed the uniaxial compression damage model based on AE. By reference of their thoughts, this paper established the damage variable $D_{C}$ based on $\mathrm{AE}$ properties:

$$
D_{C}=\frac{C_{d}}{C_{0}}
$$

where $C_{d}$ is the cumulative $\mathrm{AE}$ count at any time in the Brazilian split test, and $C_{0}$ is the cumulative $\mathrm{AE}$ count at failure.

Li et al. [2] and Liu et al. [22] modified (1) and (3) by considering the residual strength at uniaxial compression failure (multiplying (1) and (3) by correction factor $1-\sigma_{c} / \sigma_{p}$, in which $\sigma_{c}$ and $\sigma_{p}$ are the residual strength and peak strength, resp.). However, different from the uniaxial compression test, the Brazilian split test does not involve the residual strength. Therefore, the residual strength is not modified in this paper.

4.2. Damage Evolution Laws Based on the Electrical Resistivity and $A E$ Properties. The time-varying curves of the damage variables based on the electrical resistivity and AE properties were established by using (1)-(3), as shown in Figures 6 and 7. Then, the evolution laws of the damage variables in the Brazilian split test can be obtained as follows:

(1) In the Brazilian split test with the loading direction vertical to the bedding, the damage variable based on the electrical resistivity shows an obvious decrease in the compaction stage, which means the rock damage 


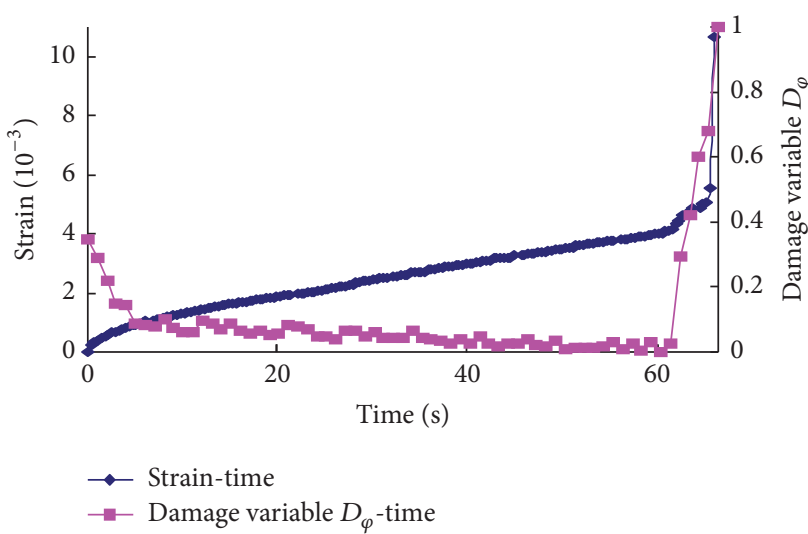

(a) Time-varying curve of the damage variable based on the electrical resistivity

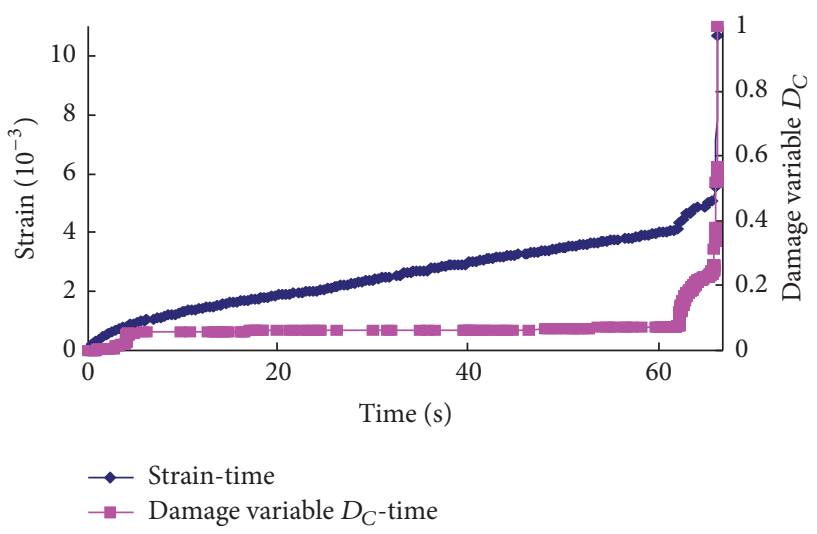

(b) Time-varying curve of the damage variable based on AE properties

Figure 6: Damage variable-time curve of samples whose loading directions are vertical to the bedding plane.

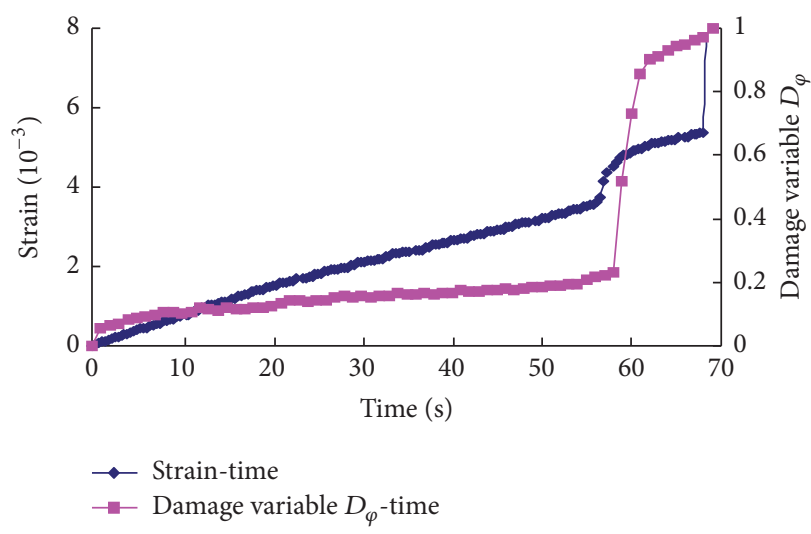

(a) Time-varying curve of the damage variable based on the electrical resistivity

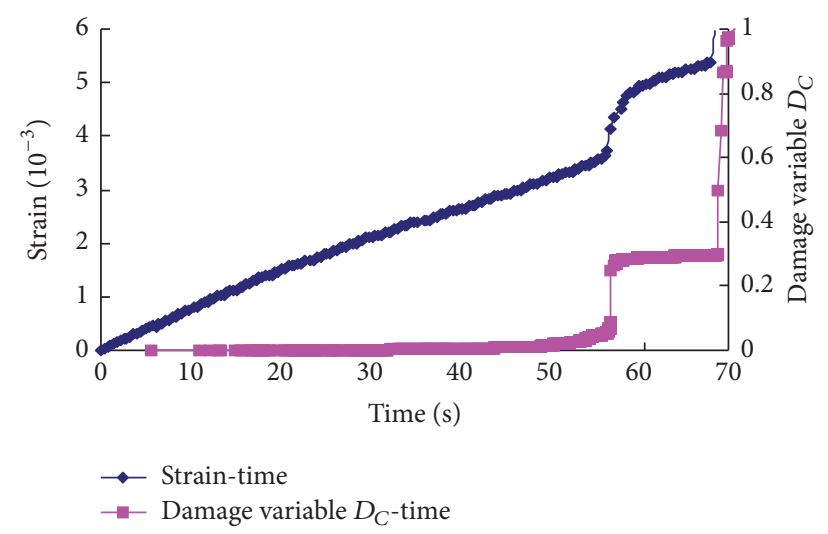

(b) Time-varying curve of the damage variable based on AE properties

FIGURE 7: Damage variable-time curve of samples whose loading directions are parallel to the bedding plane.

is in weakening stage. In this stage, the rock sample shows a density increase and overall strength improved. In the elastic deformation stage, the damage variable declines slowly without obvious changes, and the rock damage is in the quasi-linear stage. In the plastic deformation and failure stage, the damage variable rises rapidly and increases suddenly at the moment of failure, and the rock damage starts to evolve and develop rapidly. The change laws of the damage variable based on AE are basically consistent with those of the damage variable based on the electrical resistivity in the last two stages. However, the damage variable based on AE rises slightly in the compaction stage. This is because it is established based on the cumulative AE count, and the microcracks inside rock samples are compacted and closed in this stage, thus producing AE. Therefore, the cumulative AE count and damage variable based on $\mathrm{AE}$ increase. On the whole, in the Brazilian split test with the loading direction vertical to the bedding, the damage variable based on the electrical resistivity can more accurately describe the three stages of the stressstrain curve while that based on AE can not accurately respond to damage weakening in the compaction stage.

(2) In the Brazilian split test with the loading direction parallel to the bedding, both damage variables remain at a lower level without obvious changes and have no damage weakening stage in the early loading stage. As the load increases, the change laws of the two damage variables are basically consistent in the elastic deformation, as well as plastic deformation and failure stage. In the elastic deformation stage, they decline slowly without obvious changes, and the rock damage is in the quasi-linear stage. In the plastic deformation and failure stage, they rise rapidly and increase suddenly at the moment of failure. Therefore, they can accurately reflect the failure of rock samples in each stage.

(3) The two damage variables can well reflect the failure and damage evolution of rock with different loading 
directions. In particular, the damage variable based on the electrical resistivity can well reflect and accurately describe the damage weakening stage in the compaction stage.

\section{Conclusions}

On the basis of previous studies, this paper studied the electrical resistivity and $\mathrm{AE}$ properties of rock samples, as well as damage evolution based on them in the Brazilian split test, and reached the following conclusions:

(1) Rock samples showed obviously anisotropic characteristics in the Brazilian split test. The test with the loading direction vertical to the bedding and that with the loading direction parallel to the bedding showed obviously different results. The entire process of the former was mainly divided into three stages: compaction, elastic deformation, and plastic deformation and failure while the latter had no obvious compaction stage.

(2) Rock samples showed obviously anisotropic electrical resistivity and AE response properties in the Brazilian split test. Specifically, in the early loading stage (compaction stage) of the Brazilian split test with the loading direction vertical to the bedding, the electrical resistivity declined at a relatively slow rate; meanwhile, obvious AE activities appeared. However, in the early loading stage (early elastic stage without compaction stage) of the Brazilian split test with the loading direction parallel to the bedding, the electrical resistivity had no obvious changes, and AE activities barely appeared.

(3) On the basis of previous study results, the damage variables based on the electrical resistivity and $\mathrm{AE}$ properties were modified, and the evolution laws of the damage variables in the Brazilian split test were obtained. In the Brazilian split test with the loading direction vertical to the bedding, the damage variable based on the electrical resistivity showed an obvious decrease in the compaction stage, as well as an obvious damage weakening stage while that based on AE rose slightly in the compaction stage. The last two stages of the Brazilian split test with loading directions vertical and parallel to the bedding were basically consistent. Specifically, in the elastic deformation stage, both damage variables declined slowly without obvious changes, and the damage was in the quasi-linear stage. In the plastic deformation and failure stage, the two damage variables rose rapidly and increased suddenly at the moment of failure, and the damage started to evolve and develop rapidly.

(4) In conclusion, the Brazilian split test with loading directions vertical and parallel to the bedding showed obviously different results. Specifically, the stressstrain curve of the latter did not show the compaction stage; and the time-varying curve of the electrical resistivity of the latter did not show a slow decrease obviously in the early loading stage; the time-varying curve of AE properties of the former indicated obvious AE activities while that of the latter indicated few ones; the time-varying curve of the damage variable of the former showed the damage weakening stage for the damage variable based on the electrical resistivity and an abrupt increase for the damage variable based on AE properties under low load.

\section{Competing Interests}

The authors declare that there is no conflict of interests regarding the publication of this paper.

\section{Acknowledgments}

This work is supported by the National Program on Key Basic Research Project of China (973 Program) (nos. 2014CB046901, 2013CB036002, and 2015CB058101), National Major Scientific Equipment Developed Special Project (no. 51327802), National Natural Science Foundation of China (no. 51139004), the General Program of National Natural Science Foundation of China (no. 51479104), National Key Research and Development Program (no. 2016YFC0401805), Consulting Research Project of Chinese Academy of Engineering (no. 2015-05-ZD-002), and the Fundamental Research Funds of Shandong University (no. 2014HW012).

\section{References}

[1] T. Y. Nie and H. Pu, "Numerical simulation research of splitting failure of roadway under high stress," Journal of Mining \& Safety Engineering, vol. 31, no. 6, pp. 963-968, 2014.

[2] S. C. Li, X. J. Xu, Z. Y. Liu et al., "The electrical resistivity and acoustic emission response characteristic and damage evolution of sandstone during the whole process of uniaxial compression," Chinese Journal of Rock Mechanics and Engineering, vol. 33, no. 1, pp. 14-23, 2014.

[3] S.-Q. Yang and H.-W. Jing, "Strength failure and crack coalescence behavior of brittle sandstone samples containing a single fissure under uniaxial compression," International Journal of Fracture, vol. 168, no. 2, pp. 227-250, 2011.

[4] Q. Ping, Q.-Y. Ma, and P. Yuan, "Energy dissipation analysis of stone specimens in SHPB tensile test," Journal of Mining \& Safety Engineering, vol. 30, no. 3, pp. 401-407, 2013.

[5] E. Aristodemou and A. Thomas-Betts, "DC resistivity and induced polarisation investigations at a waste disposal site and its environments," Journal of Applied Geophysics, vol. 44, no. 2-3, pp. 275-302, 2000.

[6] L. Meng, M.-J. Liu, and Y.-G. Wang, "Study on the rules of electrical resistivity variation of tectonic coal in uniaxial compression experiment," Journal of the China Coal Society, vol. 35, no. 12, pp. 2028-2032, 2010.

[7] H. Wang, H. G. Ji, H. Cheng, and J. A. Wang, "Experimental study of electrical conductivity of main rocks in strata of Huaibei and Huainan coalfield under uniaxial compression," Chinese Journal of Rock Mechanics and Engineering, vol. 29, no. 8, pp. 1631-1638, 2010. 
[8] J.-N. Tu, Q. Sun, Z.-H. Jiang, L. Xue, and H.-T. Qian, "Analysis on rock resistivity variation with stress ratio at the state of critial brittle failure," Journal of the China Coal Society, vol. 38, no. 2, pp. 221-225, 2013.

[9] W. F. Brace and A. S. Orange, "Electrical resistivity changes in saturated rock under stress," Science, vol. 153, no. 3743, pp. 15251526, 1966.

[10] M. Takano, I. Yamada, and Y. Fukao, "Anomalous electrical resistivity of almost dry marble and granite under axial compression," Journal of Physics of the Earth, vol. 41, no. 6, pp. 337346, 1993.

[11] Q.-L. Yao, X.-H. Li, L.-H. He, and J. Zhou, "Strength deterioration and acoustic emission characteristics of water-bearing sandstone in uniaxial compressive experiment," Journal of Mining \& Safety Engineering, vol. 30, no. 5, pp. 717-722, 2013.

[12] S. Li, X. Yin, Y. Wang, and H. Tang, "Studies on acoustic emission characteristics of uniaxial compressive rock failure," Chinese Journal of Rock Mechanics and Engineering, vol. 23, no. 15, pp. 2499-2503, 2004.

[13] N.-B. Zhang, Q.-X. Qi, Z.-H. Ouyang, H.-Y. Li, S.-K. Zhao, and Z.-J. Xu, "Experimental on acoustic emission characteristics of marble with different stress paths," Journal of the China Coal Society, vol. 39, no. 2, pp. 389-394, 2014.

[14] V. Mlakar, F. P. Hassani, and M. Momayez, "Crack development and acoustic emission in potash rock," International Journal of Rock Mechanics and Mining Sciences \& Geomechanics Abstracts, vol. 30, no. 3, pp. 305-319, 1993.

[15] E. Eberhardt, D. Stead, B. Stimpson, and R. S. Read, "Changes in acoustic event properties with progressive fracture damage," International Journal of Rock Mechanics and Mining Sciences, vol. 34, no. 3-4, pp. 71.e1-71.e12, 1997.

[16] X. B. Yu, Q. Xie, X. Y. Li, Q. R. Wang, and Z. P. Song, "Acoustic emission of rocks under direct tension, brazilian and uniaxial compression," Chinese Journal of Rock Mechanics and Engineering, vol. 26, no. 1, pp. 137-142, 2007.

[17] Q. Xie, X. B. Yu, and D. G. Carlos, "Influence of time-delay on Kaiser effect of rock under Brazilian tests," Rock Soil Mechanics, vol. 31, no. 1, pp. 46-50, 2010.

[18] P. H. Luo, X. B. Yu, and Q. Deng, "Acoustic emission study of rocks under Brizilian test," Non-Ferrous Metals (Mining Section), vol. 62, no. 2, pp. 44-48, 2010.

[19] J. H. Fu, B. X. Huang, and C. Y. Liu, "Study on acoustic emission features of foal sample Brazilian splitting," Coal Science and Technology, vol. 39, no. 4, pp. 25-28, 2011.

[20] H. P. Xie, J. F. Liu, Y. Ju, J. Li, and L. Z. Xie, "Fractal property of spatial distribution of acoustic emissions during the failure process of bedded rock salt," International Journal of Rock Mechanics and Mining Sciences, vol. 48, no. 8, pp. 1344-1351, 2011.

[21] L. Wang, Z. Y. Tan, and Y. Zhou, "Mesoscopic simulation of the acoustic emission characteristic of coal samples in Brazilian test," Journal of University of Science and Technology Beijing, vol. 36, no. 3, pp. 3-10, 2014.

[22] B. X. Liu, J. L. Huang, Z. Y. Wang, and L. Liu, "Study on damage evolution and acoustic emission character of coal-rock under uniaxial compression," Chinese Journal of Rock Mechanics and Engineering, vol. 28, no. s1, pp. 3234-3238, 2009. 

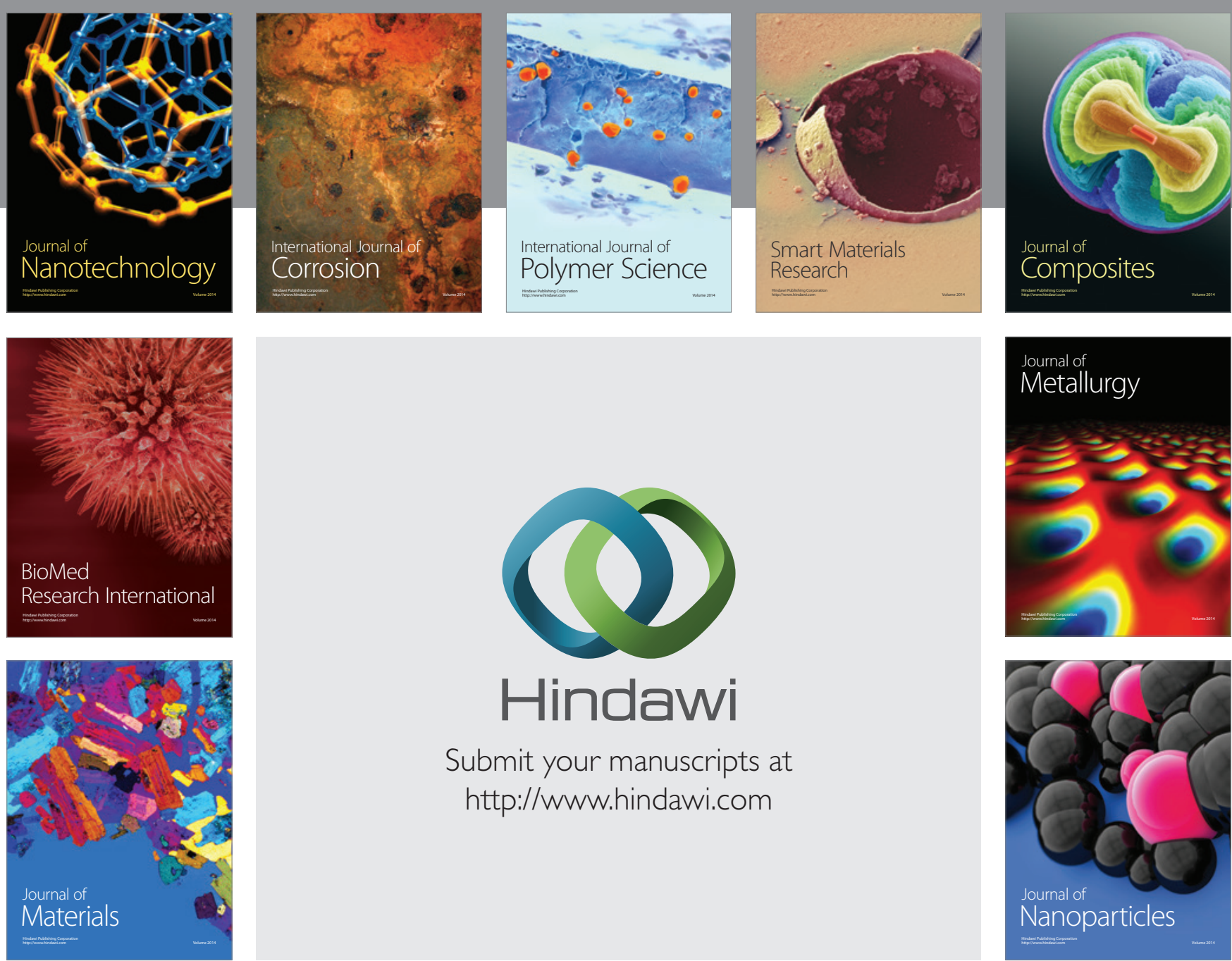

\section{Hindawi}

Submit your manuscripts at

http://www.hindawi.com

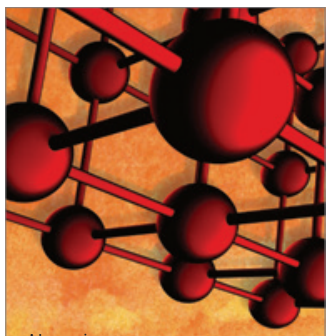

Materials Science and Engineering
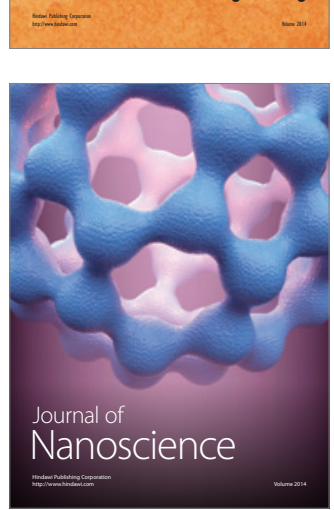
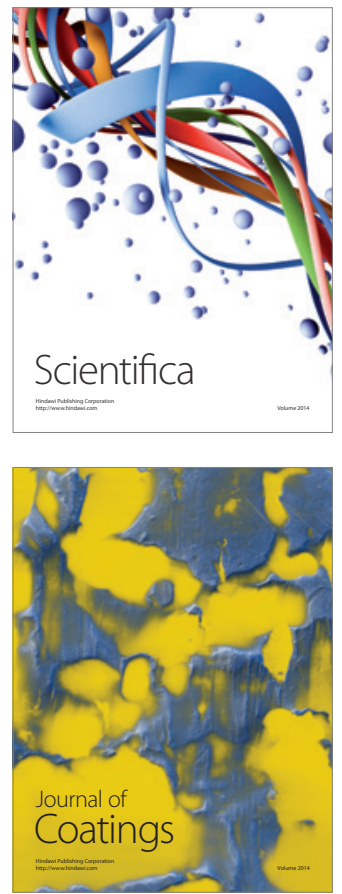
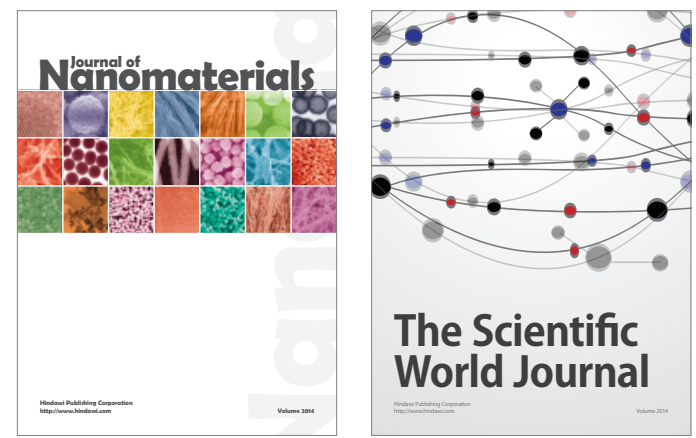

The Scientific World Journal
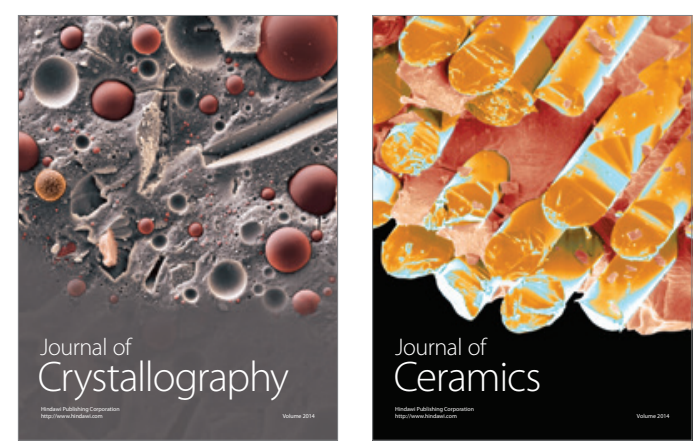
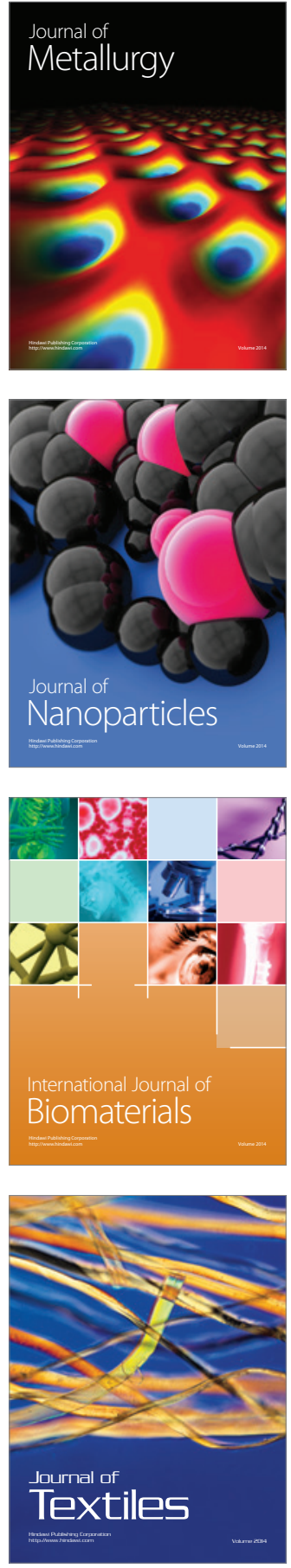